International Journal on Biological Sciences 11 (1), January-June 2020, pp. 36-46 ISSN No.: 0976-4518; NAAS Rating 3.14

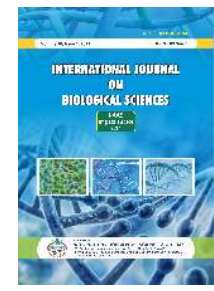

\title{
EFFICACY OF IMMUNOLOGICAL PROTOCOL TO APPRAISE THE DIAGNOSIS OF AMPHISTOME INFECTION IN LIVESTOCK
}

\author{
Syed Shabih Hassan \\ Department of Veterinary Parasitology, College of Veterinary Science \\ Guru Angad Dev Veterinary and Animal Sciences University, Ludhiana-141004 (India)
}

Review Paper

Received: 10.06.2020

Revised: 20.06.2020

Accepted: 27.06.2020

\begin{abstract}
Parasites are a major cause of disease in domestic ruminants. More than half the livestock population live in misery and suffer vast economic losses due to parasites. Among the parasitic diseases, amphistomosis is one of the major parasitic diseases causing heavy economic losses to livestock industry. Livestock production can be increased by the reduction of losses due to disease and development of new immunological approaches. Immunodiagnosis of parasitic diseases requires highly sensitive and specific tests. In many cases the identification of helminth parasites concerns their epidemiology and it is important to distinguish between species and subspecies. Conventional techniques including serology and microscopy do not always meet these requirements. However, microscopy still remain the mainstay of several diagnostic laboratories.Development of diagnostic tools have opened new avenues for a vast improvement in parasitic disease detection. A number of new serology-based assays that are highly specific and sensitive have emerged, such as agar gel precipitation, agglutination, immunodiffusion (ID), counter current immunoelectrophoresis (CCIEP), FAST-ELISA, Dot-ELISA, Sandwich-ELISA, Plate-ELISA, SDS-PAGE, Western blotting, immunoblotting etc. These approaches have revealed potentiality in parasitic disease diagnosis such as amphistome infection with increased specificity and sensitivity. The use of immunodiagnostic approaches in the identification of paramphistome infection in livestock is discussed.
\end{abstract}

Keywords: Efficacy, Appraise, Immunological protocol, Amphistomosis, Livestock.

\section{INTRODUCTION}

Parasitic diseases remain the threat to global healthcare sector, with considerable mortalities and morbidities associated with the disease. Amphistomes are an important group of parasites which causes amphistomosis. It is a disease of domestic and wild ruminants caused by digenetic trematodes of the superfamily Paramphistomoidea (Lotfy et al. 2010), which includes many genera such as Paramphistomum, Calicophoron, Cotylophoron, Explanatum, Gigantocotyle,Carmyerius etc (Hajipouret al., 2020).The effective control and treatment of amphistome parasitic diseases requires rapid, reliable and highly sensitive immune-molecular diagnostic tests, which can also serve to monitor the effectiveness of the therapeutic and prophylactic protocol.
Against some of the antigens, the body is capable of generating other complex protein molecules such as antibodies that neutralize the antigens by binding to them. Techniques that measure these antibodies or antigens provide alternative tools for diagnosis. This method of diagnosis, which uses the immunological binding reaction between antibodies and antigens, is known as immunodiagnosis. Intact immunity is fundamental for survival (Huston, 1997). Certain technological advances in the field of molecular biology were made possible in part by earlier progress in the field of immunology (Smith, 2001). It has facilitated the advances made in the field of molecular biology, the latter in turn has contributed to a better understanding of the basis for antibody diversity. An understanding of the genetic mechanisms responsible for

*Corresponding author: fish_ab@rediffmail.com 
antibody or immunoglobulin diversity requires some knowledge of antibody structure (Smith, 2001).

The immune system has two major tasks. It must protect individuals against infectious agents invading the body from outside, and at the same time it must prevent the development of abnormal cells within the body. Molecules that induce the immuneresponses are called antigens. Antigen-antibody reactions are considered basic immunodiagnostic method. This method is applied for estimation of the pathogens or protective antibodies. In addition, the steps of evolution of disease diagnosis in domestic ruminants, antibody-based immune diagnosis play a sensitive role (Ndao, 2009). There are two types of immuneresponses, one mediated by proteins called anti bodies which are responsible for resistance to infectious agents found in body fluids. The other mediated by cells called lymphocytes, is responsible for destruction of abnormal cells. Parasitological diagnosis is possible for adult amphistomes when the eggs begin to appear in the faeces while the pathology and disease occurs during early phase of infection. The immunological techniques are very sensitive and needs proper care and determination during the experiment. The methods and protocols described by many authors(Ouchterlony, 1958; Laemmli, 1970; Engvall \& Perlmann, 1971; Schuurs, 1971; Towbinet al., 1979; Garvey et al., 1983; Hudson \& Hay 1989; Stiteset al., 1994; Bailey \& Graham, 1996; Ausubel, 1997; Huston, 1997; Smith, 2001; Janarthanan \& Vincent, 2007; Swami, 2009) to make researcher follow easily and ready for independent research works in the laboratory.

\section{MATERIALSAND METHODS}

Some of the immunological approaches or techniques based on the experimental works for the diagnosis of amphistome infectious diseases are as follows:

\section{Agar Gel Precipitation}

Such technique used serum to detects antibody produced in response to infection. In this, available antigens and antibodies are put in wells in agar plates and permitted to diffuse toward one another. The immune response happens in a center well, and the antigens are placed in encompassing wells. They form an interlaced antigen-antibody complex that precipitates in the agar. When an immune response and specific antigen meet each other with proper concentrations, the precipitate will form as appearance of white line between the two wells. This line is called a precipitin line (Bailey \& Graham, 1996). This technique is specific and needs a specific antigen for each parasite.

\section{Agglutination}

If an antigen is mixed with its corresponding antibody called isoagglutinin. Here, unknown antigens will be discovered by using the agglutination test; the blood is mixed with the unknown antigen with known antibodies. Regardless of whether agglutination occurs or not, that helps to determine the antigens. In direct agglutination test, the serum is to be added to a suspension to cells that have the surface antigen to be tested (Hudson \& Hay, 1989). The clumping of cells like red blood cells in the presence of an antibody or complement. The antibody or other molecule binds multiple particles and joins them, creating a large complex. This is rapid technique but less accurate and nonspecific.

\section{Immunodiffusion}

This technique was used since 1905 and developed in to arange of highly sophisticated techniques. CarlBertilLaurell discovered $\alpha 1$-antitrypsine deficiency, introduced the electro-immuno assay around 1966 for quantitative protein analysis. When molecules such as soluble antigens diffuse from a homogenous solution into in agar gel, the concentration falls from a maximum at the solutions/gel interface to zero at the leading edge of the region penetrated. Thus, the system rapidly adjusts to give a complete antigen concentration gradient. Some where along this concentration gradient will be an antigen concentration that will give equivalence with almost any given concentration of antibody. There are two immunodiffusion methods.

Single (Simple) Immunodiffusion technique usually involves the diffusion of antigen from a solution into a gel-containing antibody. A range of antigen concentrations is placed in wells cutinagar containing the corresponding antiserumon microscopic slide. As the antigen diffuses out radially from the wells a ring of precipitation forms and appears to move out wards.

Double immunodiffusion technique involves the diffusion of both antigen and antibody (towards each other) is probably the most widely used immunochemical techniques. It may for example be used for detecting which sera or chromatographic or cell fractions, contain a particular antigen and whether 
or not two antigens areidentical, different or share antigenic determinants (Ouchterlony, 1958). 5-10mm diameter wells was cut with cork borer andremovedfrom 1-2mm thick layers of agarinapetridish and thereby filled with antigens (peripheral wells) and antisera (in central wells). The petridishesares to redinahumid chamber. The wells are observed and refilled with appropriate solutions daily. A single precipitation line between the central and the peripheral wells appear indicating that the peripheral wells contain specific serum protein. The results obtained by this method are immunoelectrophoresis is used to investigate the purity of or to detect, particular antigens in sera, culture filtrates tissue or cell extracts or fractions from any preparative procedure. The flow chart of DID are as follows.

Apply 3ml. of 1\% Agarose (prepared in 0.01 MPBS, $\mathrm{pH}=7.4$ ) poured on the cleaned slides $\downarrow$

Wells are punched in the semi-solidified gel with a puncher

About 7ulo Agis added in the central well and antiserain serial dilution in surrounding wells determining the titreofantisera $\downarrow$

Leave the slide sovernight on moist filter paper on petridishes $\downarrow$

Recharge the wells on the slides if necessary $\downarrow$ Precipitin lines appear showing positive reaction

Slides are then dried stained in $0.1 \%$ coomassie brilliant blue (Immersed the slides for 3hrs)

$$
\downarrow
$$

Then Destain the slides

(Immersed for half an hour) $\downarrow$

Then dried and stored at Room Temperature (wrap the slide by using tissue paper)

\section{Counter Current Immunoelectrophoresis (CCIEP):}

CCIEP was used for rapid diagnosis of various diseases because it provides output within a short period ( 1 to 2 hrs). In this case the antigen moves against cathodic back flow which counter the current and both antigen and antibody a rerun simultaneously in counter-current-immuno electrophoresis approach of immune-diagnosis. This technique was used extensively for the diagnosis of various diseases before the development of ELISA kits. CCIEP was performed by using $1 \%$ agarose in $0.2 \mathrm{M}$ Tris- $\mathrm{HCl}(\mathrm{pH}=8.2)$ gel at $150 \mathrm{~V}$ for 2 hrs followed by staining with $0.1 \%$ Coommasie brilliant blue G-250 and destaining in $40 \%$ methanol and $10 \%$ acetic acid. The flow chart of CCIEP are as follows.

Prepare Gel plates by the application of 3ml. of 1\% Agarose (prepared in $0.1 \mathrm{M}$ Tris- $\mathrm{HCl}, \mathrm{pH}=8.2$ ) poured on the cleaned slides

$$
\downarrow
$$

Wells are punched in the semi-solidified gel with a puncher in parallel rows

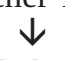

About 7ul of Agis added in one well, Antigen is added in one row and anti serain serial dilution in the parallel row to determining the titreo fantisera<smiles></smiles>

Wells with Agare connected to (-) veel ectrode and with anti sera to $(+)$ veelectrode with the help of paper wicks in CCIEP Apparatus<smiles>[AlH2]</smiles>

Samples are electrophorised at $150 \mathrm{~V}$ for one and half hour $\downarrow$

Recharge the wells on the slides with the same specification and dilution, if necessary

If precipitin lines appear showed positive (+ve) reaction

$$
\downarrow
$$

Slides are then dried Stained in $0.1 \%$ coomassie brilliant blue (Immersed the slides for 3hrs)

Then Destain the slides (Immersed for half an hour)

$$
\downarrow
$$

Then dry and store at Room Temperature

(wrap the slide by using tissue paper)

Enzyme Linked Immunosorbant Assay(ELISA): When antibody is covalently linked to an enzyme and the enzyme-linked antibody is allowed to react with immobilized antigen, the antigen-antibody reaction was visualized by change, in colour of the substrate due to enzyme action. ELISA is being used extensively for the diagnosis of several types of diseases and is one of the most sensitive and specific tests. It is a heterogenous assay, which relies on an immuno sorbent, i.e., an absorbing material that is specific for one of the reactions, to effect separation of free and bound antigens. For the preparation of antigen, the 
collected parasites were washed thoroughly, homogenized, sonicated, centrifuged, filtered and estimated its protein following Lowry (1951) method. The main difference between the regular ELISA and dot-ELISA lies in the surface used to bind the antigen of choice. Plastic plate is replaced by a nitrocellulose membrane onto which a small amount of sample volume is applied in dot-ELISA techniques. The choice of binding matrix greatly improved the specificity and sensitivity of the assay by reducing the binding of nonspecific proteins usually observed when plastic binding matrixes are used. The assay was used to quantitate both antigens and antibodies in serumor other fluids. The ELISA was conducted as per the procedure of Hudson and Hay (1989) with some modification. Checker board titration was performed to find out optimum concentration of antigen, antibody and conjugate. The antigen was immobilized on a solid phase. This antigen was allowed to react with antibody enzyme conjugate and finally substrate was added. The substrate under specific conditions developed the colour reaction. Indirect ELISA specifically labelled antibody was required for each individual antigen. The antigen was immobilized on a solid phase. The antibody was added in the next step. The antigen was allowed to react with antibody. Then anti-species globulin conjugated with enzyme was added. Finally, substrate was added to get the colour reaction. In this case a single labelled anti-species antibody was used with a variety of antisera of different specificity prepared in same species of animal. A modification of Indirect ELISA, is the antibody sandwich ELISA, which is a highly sensitive method of detecting antigen. It involves first coating the plate with specific antibody (capture antibody). The antigen solution was then added so that the antigen should bound by the capture antibody. It was followed by washing and then antibody, enzyme labeled antiglobulin and substrate as described by for the indirect techniques. In this test the intensity of the colour reaction is related directly to the amount of bound antigen. Because these tests involve the formation of antibody-antigen-antibody layers, they are called Sandwich ELISA. Sandwich ELISA was used to detect antigen when the amount in the sample is too dilute to bedetectable when directly adsorbed to the surface. The Falcon assay screening test ELISA consists of using synthetic and recombinant peptides to evaluate antibody responses to an antigen. The method has been applied to the study of helminth infection in ruminants. ELISA tests are widely used fortheimmunodiagnosisofmanybacterial,viralandpara siticinfections. In order to evaluate sensitivity and specificity of Paramphistomum antigen with test sera for each method was calculated as follows.

$$
\begin{aligned}
& \text { True negative-False positive } \\
& \text { Specificity }(\%)=\text {---------------------- X } 100 \\
& \begin{array}{c}
\text { True positive-False negative } \\
\text { Sensitivity (\%) = ------------------ X } 100 \\
\text { True positive }
\end{array}
\end{aligned}
$$

The flow charts of different types of ELISA are as follows.

\section{Indirect Dot-ELISA}

Use Greiner ELISA plate and keep ready dipsticks, antigen, sera, reagents, solution and micropipette of various ranges and keep in mind for various controls in 2-3legs of the combs

coating of Antigenon NCM pad of Dot-ELISA comb and kept over night at $4{ }^{\circ} \mathrm{C}$, Use (+)ve and (-) ve controls like normal sera/foetalcalfsera/PBS,150ul/well

In cubation in 3\% lactogenin 0.01 MPBS, $\mathrm{pH}=7.4$, at $37^{\circ} \mathrm{C}$ for $1 \mathrm{hr}$ for blocking the non-specific antigen bindingsites, $150 \mathrm{ml} /$ well

Two washings in 0.01 MPBS ( $\mathrm{pH}=7.4$ ) of 2 min each. In cubate the combinanti-sera (dilute in 0.01 MPBS, $\mathrm{pH}=7.4$ ), at $37^{\circ} \mathrm{C}$ for $1 \mathrm{hr}, 150 \mathrm{ml} /$ well,

$\downarrow$
Three washings in $0.01 \mathrm{MPBS}(\mathrm{pH}=7.4)$ of 2 min each.
$\downarrow$

Incubate the comb with HRPO conjugate (in 0.01 MPBS, $\mathrm{pH}=7.4$ ) for $1 \mathrm{hr}$ at $37^{\circ} \mathrm{C}, 150 \mathrm{ml} /$ well

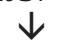

Three washings in 0.01 MPBS (pH=7.4) of 2 min each. $\downarrow$

Incubate the combin 33'-Diamino-benzidinehydro chloride (5mg/10ml PBS+10ìl 0.06\% H2O2) for 5-15 minute, $150 \mathrm{ml} /$ well

\section{Stop the Reaction by using DW}

Development of dark brown spot indicated positive reaction.

\section{Sandwich-ELISAfor the Detection of Coproantigen} Use Greiner ELISA plate and keep ready dipsticks, antigen, sera, reagents, solution, micropipette of 
various ranges and keep in mind for various $(+)$ ve or (-)ve controls in 2-3 legs of comb

$$
\downarrow
$$

Coating of antibodies on NCM pads of dipsticks stored at $4^{\circ} \mathrm{C}$ for overnight. Use (+)ve and (-)ve controls like normal sera/foetal calf sera/PBS,150ul/well

$$
\downarrow
$$

Incubation in 3\% lactogen in 0.01 MPBS, $\mathrm{pH}=7.4$, at $37^{\circ} \mathrm{C}$ for $1 \mathrm{hr}, 150 \mathrm{ml} /$ well,

Two washings in $0.01 \mathrm{MPBS}, \mathrm{pH}=7.4$ of 2 min each. $\downarrow$

Incubate the dipsticks in Coproantigen (CAg) in 0.01 MPBS, $\mathrm{pH}=7.4$

Two washings in 0.01 MPBS, pH=7.4 of 2 min each.

Incubate the combsinanti-sera (dilutein 0.01 MPBS, $\mathrm{pH}=7.4$ ) at $37^{\circ} \mathrm{C}$ for $1 \mathrm{hr}, 150 \mathrm{ml} /$ well

Three washings in 0.01 MPBS, $\mathrm{pH}=7.4$ of 2 min each.

Incubate the dipsticks (comb) with HRPO conjugate (in 0.01 MPBS, $\mathrm{pH}=7.4$ ) for $1 \mathrm{hr}$ at $37^{\circ} \mathrm{C}, 150 \mathrm{ml} /$ well $\downarrow$

Three washings in 0.01 MPBS, $\mathrm{pH}=7.4$ of 2 min each.

Incubate the combin 33'- Diamino-benzidinehydro chloride (5mg/10ml PBS+10ìl0.06\% H2O2) for 5-15 min, $150 \mathrm{ml} /$ well

Stop the Reaction by using DW

Development of dark brown spot indicated positive reaction.

\section{Plate-ELISA}

Use Greiner ELISA plate and keep ready antigen, sera, reagents, solution, micropipette of various ranges and keep in mind for various (+)ve or (-)ve controls of normal sera/foetal calf sera in 3-4 wells

Coating of Antigen (dilutein Coating buffer), $50 \mathrm{ml} /$ well, overnight incubation at $4^{\circ} \mathrm{C}$

3 washings of $5 \mathrm{~min}$ each in $0.1 \%$ PBST-Tween-20 (Total $15 \mathrm{~min}$ )

Blocking with 2\% Lactogen or 2\% BSA (dilutein 0.05\% PBST Tween-20), $350 \mathrm{ml} /$ well, Incubation for $2 \mathrm{hr}$ sat $37^{\circ} \mathrm{C}$
3 washings of $5 \mathrm{~min}$ each in $0.1 \%$

PBST-Tween-20 (Total $15 \mathrm{~min}$ )

$$
\downarrow
$$

(dilutein $0.05 \%$ PBST-Tween-20) incubation for 1 or 2 hrs at $37^{\circ} \mathrm{C}$

$$
\downarrow
$$

3 washings of 5 min each in $0.1 \%$ PBST-Tween-20 (Total15min)

$$
\downarrow
$$

Incubation with HRPO Conjugate (dilutein 0.05\%

PBST-Tween-20) for $1 \mathrm{hr}$ at $37^{\circ} \mathrm{C}, 50 \mathrm{ml} /$ well<smiles>[CH]1[CH]CC1</smiles>

3 washings of 5 min each in

0.1\% PBST-Tween-20 (Total15min)

$$
\downarrow
$$

Substrate (OPD) incubation for 5 to $15 \mathrm{~min}$, $50 \mathrm{ml} /$ well (10mg OPD in $10 \mathrm{ml}$ substrate buffer) $\downarrow$

Stop the Reaction by using 2 MH2SO4 (25ml/well)

Read at 405 or $492 \mathrm{~nm}$ by using ELISA Reader

\section{Sodium Dodecyl Polyacrylamide Gel Electrophoresis (SDS-PAGE):}

The antigens can be subjected to fractionation by SDSPAGE using discontinuous buffer system of Laemmlli (1970) to study the structural polypeptide profile in the antigens. It is rapid method, low cost, reproducible for quantifying, comparing and characterizing proteins. It separate protein based primarily on their molecular weight. It binds the hydrophobic portions of a protein disrupting its folded structure and allowing it to existstably in solution in an extended confirmation. As a result, length of SDS Protein complex is proportional to its molecular weight. Slab gels more widely used than tube gels, since many samples can be run onthesamegel,therebyprovidinguniformityduringpoly merization,stainingand destaining, For analytical applications, mini slab gels more useful due to increased resolution and reduced time \& materials required. The application of SDS-PAGE determines molecular weight, protein purity, protein concentration, detect proteolysis, protein modification, identify immunoprecipitated protein and separate radioactively labeled protein, protein concentration including antigen for antibody production.

SDS-PAGE was standardized by preparing $0.75 \mathrm{~mm}$ thick discontinuous polyacrylamide ge1 (10\% resolving ge1and 4\% stacking gel as per the 
requirement) using $16 \times 20 \mathrm{~cm}$ plates. Slots were made in stacking gel using 15 teeth teflon comb of $0.75 \mathrm{~mm}$ thickness. Protein concentration in antigens was adjusted the, antigens were diluted with sample buffer. Standard molecular weight markers such as Myosin, Rabbit muscle-205 kDa, Phosphorylase b97.4kDa,BSA-66kDA,Ovalbumin-43kDa and Carbonicanhydrase-29kDa was used for determining the molecular weights of different polypeptides. Mixtures were kept in boiling water bath for 5 minutes followed by cooling. Around $60 \mathrm{ml}$ of the mixture of these samples was loaded in the wel1s of the stacking gel. The electrophoresis is being carried out in electrode buffer by using Bangalore Genei slab gel apparatusor Biorad apparatus at a constant current of 60 volts for about 1-2 hours, keeping the whole apparatusinrunningmodeuntilthebromophenolbluedy ereachedthetopedgeoftheresolvinggel. Then, the current was increased at a constant voltage to 150 volts and current $0.02-0.04 \mathrm{~A}$. It took about 5-6 hours till the bromophenol b1ue reached approximately $5 \mathrm{~mm}$ above the bottom edge of the resolving gel. After completion, current supply was stopped and removed the stacking gel and separate the resolving gel from glass plates. Gel was stained in coomassie brilliant blue R-250 staining solution by keeping it overnight in the solution at room temperature $\left(25-30^{\circ} \mathrm{C}\right)$. Excess stain in the gel was removed by keeping it in the destaining solution with frequent changes till the polypeptide bands of antigens became clearly visible in the gel. At last, gel was preserved in $7 \%$ acetic acid solution for analysis and measurement.

\section{Western Blotting}

The proteins resolved by SDS-PAGE can be transferred electrophoretically on nitro cellulose membrane(NCM) following the method of Towbin et al 1979 using semi-dry electrophoretic apparatus (Atto Corporation, Japan). Transfer Immuno-blotting of the bands on NCM using sera of high titre, with dilution value and HRPO conjugate dilution using constant 100 Volt and current $0.25 \mathrm{~A}$ for 3 hrs. Then, NCM sheet after blotting was transferred to blocking solution, 3\% lactogen in PBS for 2 hrs and kept at room temperature with constant shaking. Then membrane was transferred in serum dilution and incubate at room temperature for $1 \mathrm{hr}$. Then membrane after 2 washings was incubated in PBS of 2 minutes each with conjugate dilution, for $1 \mathrm{hr}$ at room temperature. Again, the membrane was washed thrice in PBS and kept for 5-15 minutes in substrate solution (5mg of 3'-3'-Diamino- benzidine hydrochloride $/ 10 \mathrm{ml}$ PBS $+10 \mathrm{ll}$ of $0.06 \%$ $\mathrm{H}_{2} \mathrm{O}_{2}$ ). On appearance of band, the NCM sheet was washed indistilled water and preserved by drying.

\section{The protocol in brief was as under}

The NCM and six sheets of No.3 filter papers were cut according to the size of the gel. The NCM sheet was dipped in triple glass distilled water and filter paper sheets in transfer buffer for about 30 minutes. The gel was separated from glass plates after electrophoresis and was shifted directly into the transfer buffer. It was kept in this buffer for about 10 minutes. Now, the semidryelectrophoretic apparatus was opened and three sheets of No. 3 filter papers were kept over the bottom electrode (anode) and over these the NCM sheet was placed. The SDS polyacrylamide gel was positioned carefully over the NCM sheet and was covered by the remaining three sheets of No.3 filter paper. The air bubbles were gently squeezed out by rolling a smooth glass rod over the surface. The semi-dry electrophoretic apparatus was closed and connected to the power supply assembly adjusting a constant current of 0.8 milliampere $(\mathrm{mA}) / \mathrm{cm}^{2}$ of the gel for about 60 minutes. To confirm the transfer of polypeptide bands from SDS polyacrylamide gel to the NCM sheet, a strip of the NCM sheet was cut from the place where proteins of standard molecular weight were to be transferred. The strip was stained with 0.1 percent amido black 10-B solution for 3-5 minutes and thereafter destained by keeping in destaining solution till the black coloured protein bands were visible indicating transfer of proteins on the NCM sheet.

\section{Immunoblotting}

Immunoblotting was carried out as per the method described by Bose \& Daemen (1992) with slight modifications. The protocol in brief was as under:

The NCM sheet on which polypeptide bands were transferred from SDS polyacrylamide gel was placed in transfer buffer solution and washed twice for 5 minutes each by constant shaking. The washed NCM sheet was transferred into the blocking solution and incubated for an hour at room temperature $\left(25-27^{\circ} \mathrm{C}\right)$. The NCM sheet was washed three times (each time for 5 minutes) with the washing solution. The NCM was dipped in serum diluted to 1:100 in diluting solution and incubated at room temperature $\left(25-27^{\circ} \mathrm{C}\right)$ for about $1 \mathrm{hr}$. The serum used in above step was the high titred serum collected from rabbits after immunization with whole somatic amphistomeantigen. The sheet was washed three times with the washing solution as 
mentioned above. The washed sheet was incubated for an hour at room temperature $\left(25-27^{\circ} \mathrm{C}\right)$ with goat antirabbit IgG conjugated with horse radish peroxidase (HRP Sigma, USA) diluted to 1:2000 in the diluting solution. The sheet was again washed three times with the washing solution. Finally, the NCM sheet was kept for about 10 minutes in the substrate solution as the bands appeared; the sheet was then washed in distilled water and preserved by drying. Molecular weights of different immunogenic polypeptides of amphistome antigens were calculated by regression analysis as mentioned below.

\section{Determination of Molecular Weights of Different Polypeptides:}

Standard marker proteins (Sigma Chemical Co, USA) with molecular weights ranging from 29 to $205 \mathrm{kDa}$ is generally used for the estimation of molecular weights of different polypeptides in the antigens. Marker proteins were loaded in the adjacent wells and run simultaneously on the same gel on which the antigens were going to be fractionated. After completion of electrophoresis, staining and background destaining, the relative mobilities ( $\mathrm{Rf}$ values) of polypeptide bands of different antigens and marker proteins was calculated by the following formula:

$$
\text { Rf }=\text { Migration distance of protein(mm) }
$$

Calibration curve was constructed by plotting the Rf values of the marker proteins against their log molecular weights using regression analysis.

Regression equation was drawn between the independent variable (log value of the standard molecular weight) and the dependent variable (relative mobilities) of the individual molecular weights of standard molecular weight markers, with the help of the following formula:

$$
\begin{aligned}
& \mathrm{Y}=\mathrm{a}+\mathrm{bx} \\
& \text { Where, } \mathrm{Y}=\log \mathrm{y} \\
& \mathrm{Y}=\text { standard mol. wt. } \mathrm{a}=\text { constant factor } \\
& \mathrm{b}=\text { regression coefficient } \mathrm{x}=\text { relative mobility }(\mathrm{Rf})
\end{aligned}
$$

The molecular weight of the individual polypeptides in the different antigenic profiles were calculated by putting the value of the $\mathrm{Rf}$ in the regression equation and calculating the value of $y$.

\section{RESULTS AND DISCUSSION}

In fact, classical methods for parasitic diseases treatment depend on anti parasitic chemical drugs with their drawbacks (Forwood et al., 2013). In addition, some considerations should be taken such as $\mathrm{LD}_{50}$ of drug of choice, method of application, sensitivity of host to chemotherapy (Noga, 2012). The important issue in amphistome infection was to explore the possibility to have specific immunological approaches that could detect an early stage of infection. It is interesting to note that above immunological protocol is effective in the diagnosis of trematode infection including amphistomosis, although the molecular weight of different diagnostic molecules are same, the biochemical nature of those is quite different.

Agar gel precipitation test using serum which detects antibody produced in response to infection where as, agglutination test is widely used as a laboratory method to identify certain antibodies and antigens. It is based on the ability of a specific serum to cause agglutination of a suitable system and used in the diagnosis of infections. The author evaluated double immune diffusion (DID) in respect of anti-P.epiclitum and anti-G. crumenifer rabbit hyperimmune sera. It was tested against somatic antigen of P. epiclitum and $G$. crumenifer by performing double immunodiffusion test (DID) and counter current immuneelectrophoresis (CCIEP) following method described by Ouchterlony (1958) and Yadav \& Gupta (1995). White precipitin lines were observed after third booster immunization. The white precipitin line showed the presence of raised antibody level against $P$. epiclitum and $G$. crumenifer antigen with hyperimmune sera. During the conduction of DID test, the author observed precipitin line between the antigens and experimental sheep sera. The author evaluated counter current immune-electrophoresis (CCIEP) in respect of the hyperimmune sera of rabbits after $4^{\text {th }}$ booster injection showed 2-3 white precipitin arcs against somatic antigen of $P$. epiclitum and $G$. crumenifer. It reveals the presence of antigenic moieties. The author also observed during the evaluation of CCIEP test in respect of experimentally infected sheep sera of 10 wpi showed a single white precipitin line against somatic antigen of $P$. epiclitum when subjected to counter current immunoelectrophoresis (CCIEP) which revealed its efficiency in diagnosis.

The important characteristics of serodiagnostic techniques as immunological assay as its highly 
sensitive approach. In indirect ELISA the significant antibody response was detected between $2^{\text {nd }}$ and $3^{\text {rd }} \mathrm{Wpi}$ which was $3^{\text {rd }}$ and $4^{\text {th }}$ wpi in Dot-ELISA test. Sensitivity of most serological assays is satisfactory but specificity remain hampered due to cross reactivity with other parasites infection in domestic ruminants by applying ELISA test. Dot-ELISA is commonly used as an immunological assay by different scientist and researchers. The difference between the regular ELISA and Dot-ELISA is represented as the surface used to bind the antigen of choice. In Dot-ELISA, the plastic plate is replaced by a nitrocellulose membrane (NCM). The choice of binding matrix greatly improved the specificity and sensitivity of the assay by reducing the binding of non-specific proteins which was usually observed (Adams, 2004).Dot-ELISA test are quick and the results can be easily read. As far as regular ELISA is concerned, it was used to decide the amount of specific antibodies agents available in blood tests which were accomplished in 96-well microtiter plates. The bottom of every well was enveloped with a protein which will join to the antibody to quantify. Every well contains a different serum. Negative and positive control serum was remarked through the 96 samples. After a short time, the serum will be removed, and weakly adherent antibodies are washed off with a series of buffer washing. ELISA test needs little concentration of antibodies and it is an early diagnostic technique. The author evaluated the efficacy of indirect Dot-ELISA in 12 leg NCM combs which was standardized for the detection of anti- $P$. epiclitum antibodies in immunized rabbit using somatic antigen of $P$. epiclitum ranging from $10 \mathrm{ng} / \mu \mathrm{l}$ to $2 \mu \mathrm{g} / \mathrm{ml}$, HRPO conjugate dilution from 1:100 - 1: 5000 and sera dilution from 1:200 - 1: 32000. Development of dark brown spot indicated positive reaction. The optimum concentration of antigen was found between 50-100ng/ $\mu \mathrm{l}$, HRPO conjugate dilution (1:500 and 1:1000) and sera dilution at $1: 400$ to $1: 800$. Best results obtained at serum dilutions 1:400. Lactogen was used because it is cheap and easily available. A total of 200 clinical/field sera samples and weekly experimental sheep sera were tested through indirect Dot-ELISA test and found very efficient in testing during field condition. Dot-ELISA findings will be exploited for the early detection of Paramphistomum antibodies in infected animals at large scale so that future preventive strategies may be undertaken.

Cornelissen et al.(2001) have reported high specificity by ELISA with sera from experimentally infected cattle and sheep, but the specificity was low, when sera were collected from naturally infected animals. Immunodominant antigen was not crossre active in ELISA test with sera of sheep experimentally infected with $P$. epiclitium. During the study of paramphistomosis, the author performed indirect Plate-ELISA in 96 well microtitre plate (Greiner) as described by Engvall \& Perlman (1971) and Njau \& Nyindo (1987) with some modification. ELISA test is used to quantitatively detect an antigen (i.e., toxin or foreign substance) within a sample. Most ELISAs are run on microplates, with the bottom of the microplate serving as the solid surface to which an antigen of interest attaches either directly or via an antibody. ELISA microtiter plate readers are typically used by researchers to read and analyze multiple plates simultaneously and obtain accurate ELISA measurements at high throughput. In fact, Engvall and Perlman (1971) invented a method that revolutionized medicine called the ELISA test. The method uses antibodies to seek out the presence of hormones or viruses. The detection antibody is coated onto the plate surface before the protein of interest is added, is developed and tested on several substrates for the proof of concept in Sandwich-ELISA (Kato et al., 1977). In indirect ELISA, a secondary antibody is added for detection purposes, was developed and used to detect serum albumin (Lindstrom\& Wagner, 1978).During the present examination of ELISA efficacy, Plate-ELISA was standardized for the detection of anti-P. epiclitum rabbit sera using somatic antigen of $P$. epiclitum ranging from $1 \mu \mathrm{g} / \mathrm{ml}$ to $10 \mu \mathrm{g} / \mathrm{ml}$, HRPO conjugate dilutions $1: 1000$ to $1: 8000$ and sera dilution from $1: 50$ to $1: 1,60,000$. The optimum concentration of antigen was observed to be $2 \mu \mathrm{g} / \mathrm{ml}$, HRPO conjugate dilution 1:1000 and sera dilution at 1:200 and 1:400. The immune response of anti-P. epiclitumanti bodies in experimental sheep were recorded. The author also finds immune response of experimental sheep sera in ELISA using purified fraction of Paramphistomum epiclitum \& Gastrothylax crumenifer antigen by seraloe 6-B gel filtration chromatography and SDS-PAGE purified specific immunodominant polypeptides of $P$. epiclitum (MW 36.6 and $38.8 \mathrm{kDa}$ ) are very much important for paramphitomosis detection in experimentally infected animals as well as clinical/field samples. A total of 222 sera samples were tested by applying plate-ELISA, out of the total, 106 samples were found to be positive with the prevalence rate of $47.75 \%$, which showed the efficiency of Plate-ELISA in diagnosis of 
paramphistomosis in ruminants. The author conducted SDS-PAGE and Immunoblotting techniques in the laboratory for finding out the immunodominant antigen of $P$. epiclitum and $G$. crumenifer. Paramphistomum epiclitum showed five immunodominant polypeptides (viz; 38.8, 36.6, 34.4, 31.0, and $21.2 \mathrm{kDa}$ ) where as two (34.4 and $21.2 \mathrm{kDa}$ ) specific immunodominant polypeptides in $G$. crumenifer using experimentally infected sheep sera. The specific immunodominant polypeptides of $P$. epiclitum of MW 36.6 and $38.8 \mathrm{kDa}$ were identified for diagnostic purposes using experimentally infected sheep sera after immunoblotting.

When comparing the efficiency and application of indirect Plate-ELISA and Dot-ELISA,itwas observed that indirect Plate-ELISA is detecting infection one week earlier, however, the field applicability of Dot ELISA is higher than the in direct-ELISA. It was also observed that the antigen coated dots can be stored for 80 days in room temperature. The indirect PlateELISA was the most sensitive tes; however, a draw back of this test is the need of an absorbance reader, which is expensive and therefore, difficult to have in laboratories with limited resources. On the other hand, Dot-ELISA test can easily be setup in a moderately equipped laboratory. The test proved to be useful in field diagnosis, considering the advantage of eliminating the use of an absorbance reader. The testis also cheaper than indirect-ELISA.The benefits of DotELISA technique include its ease of use, its rapidity, and the ease of result interpretation. It is fast, and cost effective and more importantly can be used in the field. For all these reasons, Dot-ELISA has been and still is extensively used in the detection of parasitic diseases in livestock. In spite of the fact that International Office of Epizootics (OlE) have also recommended to develop diagnostic methods for parasitic diseases, which should be simple, cheap and useful under field conditions. The DID, IEP and ELISA have been found suitable and test of choice for the serodiagnosis of trematode infection including amphistomosis. Now, there is a need to take further step of using large number of sera samples from known positive and negatives era samples for the evaluation of specificity of immunodominant antigen.

\section{CONCLUSION}

The conventional methods for diagnosis of parasitic infections should be considered as basic tools for identification of ruminant parasites. The benefits of immunodiagnostic assays such as SDS-PAGE, which is rapid technique, low cost, reproducible for quantifying, comparing and characterizing proteins and separate protein based primarily on their molecular weight. The most reliable immunoblotting techniques are considered for electrophoretic transfer of resolved protein by SDS-PAGE on nitrocellulose membrane (NCM). Molecular tools and electron microscopes are considered the excellent new trends in the diagnosis of the parasitic infections in ruminants. ELISA microtiter plate readers were efficiently used by researchers to read and analyze multiple plates simultaneously and obtain accurate ELISA measurements at high throughput. Also, the benefits of ELISA include its ease of use, its rapidity, and the ease of result interpretation. It is fast, and cost-effective and more importantly can be used in the field. For all these reasons, Dot-ELISA has been and still is extensively used in the detection of parasitic infection in livestock. The present study revealed that ELISA and immunoblot had better sensitivity and specificity than DID and CCIEP due to the use of nitrocellulose membrane and showed that the assay was successfully reproducible. The DID, IEP and ELISA have been found suitable and test of choice for the serodiagnosis of trematode infection including amphistomosis. Hence, the early diagnosis of parasitic infections in ruminants must be considered an important solution to prevent from diseases in ruminants.

\section{ACKNOWLEDGEMENTS}

Author is thankful to Science \& Engineering Research Council, Department of Science \& Technology, Ministry of Science \& Technology, Govt. of India New Delhi for financial support in the form of DST-SERCFAST-Track project and Guru Angad Dev Veterinary and Animal Sciences University, Ludhiana, for facilities provided.

\section{REFERENCES}

1. Adams, (2004). In Bondad-Reantaso, Margaret and Subasinghe, R.P. (eds.). Diseases in Asian Aquaculture VI. Fish Health Section, Asian Fisheries Society, Manila, Philippines.505 pp.

2. Ausubel, F.M. (1997). Short Protocols in Molecular Biology, Second Edition, John Wiley \& Sons. Harvard Medical School.

3. Bailey, A., and Graham, S. (1996). Ouchterlony Double Immunodiffusion". In Walker, John M. 
The Protein Protocols Handbook (pdf). VII: Immunochemical Techniques. Totowa, New Jersey: Humana Press. pp. 749-752.

4. Bose, R., and Daemen, K. (1992).Demonstration of the humoral immune response of horses to Babesia caballi by Western blotting. International Journal for Parasitology.22: 627-630.

4. Cornelissen, J.B., Gaasenbeek, C.P., Borgsteede, F.H., Holland, W.G., Harmsen, M.M,, and Boersma, W.J. (2001). Early immunodiagnosis off asciolosis in ruminants using recombinant Fasciola hepatica cathepsin Llike protease.Vet Parasitol, 31:728.

6. Engvall, E., and Perlmann, P. (1971). Enzymelinked immunosorbent assay (ELISA) quantitative assay of immunoglobulin G. Immunochemistry. 8 (9): 871-874. DOI: 10.1016/0019-2791(71)90454-X.

7. Forwood, J.M, Harris, J.O. and Deveney, M.R. (2013). Efficacy of bath and orally administered praziquantel and fenbendazole against Lepidotremabidyana Murray, a monogenean parasite of silver perch, Bidyanusbidyanus (Mitchell). J Fish Dis.25(11):3046-3052.

8. Garvey, J.S., Cremer, N.E., and Sussdorf, D.H. (1983). Methods in Immunology, 3rd ed., Benjamin / Cummins Publishing, London.

9. Hajipour, N., Mirshekar, F., Hajibemani, A., Ghorani M.(2021).Prevalence and risk factors associated with amphistome parasites in cattle in Iran. Vet. Med. Sci. 7(1):105-111. doi: 10.1002/vms3.330.

10. Hudson. L., and Hay F.C. (1989). Practical Immunology, 3rd ed., Blackwell Publishing, London.

11. Huston, D. P. (1997). The Biology of the Immune System., JAMA. 278(22):1804-1814. doi:10.1001/jama.1997.03550220010004

12. Janarthanan, S. and Vincent, S. (2007). Practical Biotechnology: Methods and protocols, University Press.

13. Kato, K., Hamaguchi, Y., Okawa, S., Ishikawa, E., and Kobayashi, K. (1977). Use of rabbit antiboty IgG bound onto plain and aminoalkylsilyl glass surface for the enzyme- linked sandwich immunoassay. J Biochem.82(1):261-6. doi: 10.1093/ oxfordjournals. jbchem.a131678.

14. Laemmli, U. K. (1970). Cleavage of structural proteins during assembly of the head of bacteriophage. Nature, 227, 630-684.

15. Lindstrom, P., and Wager, O. (1978). IgG autoantibody to human serum albumin studied by the ELISA-technique. Scand J Immunol. $7(5): 419-25$. doi: $10.1111 / \mathrm{j} .1365$ 3083.1978.tb00472.x.

16. Lotfy, W.M., Brant, S.V., Ashmawy, K.I., Devkota, R., Mkoji, G.M. \&Loker, E.S., (2010).A molecular approach for identification of paramphistomes from Africa and Asia, Veterinary Parasitology. 174(3-4), 234-240.doi: 10.1016/j.vetpar.2010.08.027.

17. Lowry, O. H., Rosbrought, N. J., Farr, A. L. and Randall, R. J. (1951) Protein measurement with the folin phenol reagent. J. Biol. Chem., 193, 265275.

18. Ndao, M. (2009). Diagnosis of parasitic diseases: old and new approaches, Hindawi publishing Corporation Interdisciplinary perspectives on infectious diseases. Article ID 278246, 15 pages.DOI: 10.1155/2009/278246

19. Njau, B.C., and Nyindo, M. (1987a). Humoral antibody response of rabbits to Rhipicephalusappendiculatus infestation. Res. Vet. Sci., 43(2):271-272.

20. Njau B.C., and Nyindo, M. (1987b). Detection of immune response in rabbits infested with Rhipicephalus appendiculatus and Rhipicephalus evertsievertsi. Res Vet Sci.43(2):217-221.

21. Noga, E. J. (2012).Amyloodiniumocellatum. In Fish Parasites - Pathobiology and Protection (ed. Woo, P.T. K. and Buchmann, K.), pp. 19-29. CAB International, Wallingford, UK.

22. Ouchterlony, O. (1958). Diffusion-in-gel methods for immunological analysis. Progress Allergy., 5:1-78.

23. Schuurs, A. (1971). Immunoassay using antigenenzyme conjugates. FEBS Letters.15 (3): 232-236.

24. Smith, J.A. (2001). Current Protocols in Molecular Biology, John Wiley \& Sons, Inc. 11.0.1-11.0.3. 
25. Stites, D.P., Terr, A.L., and Parslow, T.G. (1994). Basic and Clinical Immunology, Prentice Hall Publishing, Canada.

26. Swami, P.M. (2009). Lab Manual of Biotechnology. Rastogi Publications, Meerut.

27. Towbin, H., Staehelin, T. and Gordon, J. (1979).Electrophoretic transfer of proteins from polyacrylamide gels to nitrocellulose sheets: procedure and some applications. Proc. Natl. Acad. Sci., USA., 76, 4350-54.

28. Yadav, S.C. and Gupta, S.C. (1995). Immunodiagnostic moieties somatic, excretory/secretory antigens of $F$. gigantica, India. J. of Expt. Biol., 33: 828-834. 



\section{INVITATION OF RESEARCH ARTICLES for PUBLICATION in NESA Journals}

INTERNATIONAL JOURNAL ON AGRICULTURAL SGIENGES

ISSN N0. 0976-450X | NAAS RATING 2.60

INTERNATIONAL JOURNAL ON ENUIRONMENTAL SGIENGES

ISSN N0. 0976-4534 | NAAS RATING 3.06

INTERRATIONAL JOURNAL ON BIOLOGICAL SCIENGES

ISSN N0. 0976-4518 | NAAS RATING 3.14

\section{INDIAN JOURNAL OF UNANI MEDICINE \\ ISSN N0. 0974-6056}

These JOURNALS ON DIFFERENT SUBJECTS are being published by this Academy. Send your manuscripts for peer-review by e-mail. THE AUTHORS MUST MENTION ADDRESS, Contact Nos. and E-MAIL ID in their forwarding letter. Proof will be sent for correction before publishing. A pledge for originality will be signed by the authors. Five sets of reprints will be dispatched within 30 days after the receipt of the PROCESSING FEE. alongwith a press print soft copy of final version of manuscript. All remittances are to be sent by a crossed Bank Draft in favour of NATIONAL ENVIRONMENTAL SCIENCE ACADEMY payable at NEW DELHI.

For further details and NOTES FOR AUTHORS,

please contact Academy at

nesapublications@gmail.com nesapub@yahoo.co.in 